\title{
Alguns apontamentos e um futuro aberto: sociedade da informação e do conhecimento, convergência tecnológica, diversidade midiática e ciberjornalismo
}

\begin{abstract}
RESUMO
No ambiente da Sociedade da Informação, o jornalismo é mais "fiscalizado" e precisa, em tal cenário, redobrar compromissos que o tornaram imprescindível para a informação e o conhecimento sobre o entorno social de forma imediata, massiva e planetária, em períodos cada vez mais curtos. Com tal perspectiva, o artigo se debruça sobre algumas paisagens para o jornalismo no século 21, sem cultuar certezas absolutas. Assim, trata da atividade profissional no quadro da SI - para alguns também uma Sociedade da Informação e do Conhecimento (SIC) - e dentro de um cenário povoado pela simultânea concentração e diversidade midiáticas, pela convergência tecnológica e pelo novo ambiente do ciberjornalismo.
\end{abstract}

\section{PALAVRAS-CHAVE}

Jornalismo

Ciberjornalismo

Profissão

\begin{abstract}
In the environment of the Information Society, journalism is more "supervised" and, in such a scenario, needs to redouble commitments that have made it vital for the information and knowledge about the social surroundings in immediately, massive and planetary ways, in ever shorter periods. With this perspective, this article focuses on some scenarios for journalism in the 21st century, without worship absolutes certainties. Thus, it is about the professional activity within the IS - for some also an Information and Knowledge Society (IKS) - and within a scenario populated by simultaneous media concentration and diversity, technological convergence and the new cyber journalism environment.
\end{abstract}

\section{KEYWORDS}

Journalism

Cyber Journalism

Profession

Francisco José Castilhos Karam

Professor do Programa de Pós-Graduação em Jornalismo da UFSC/SC/BR.

fikaram@terra.com.br 
A atividade jornalística vem sendo analisada e criticada ou reforçada por distintos autores que, em sucessivos debates e produções, têm chamado a atenção para a relevância da informação (ou a perda dela) do tipo jornalística em novo cenário, em que a profissão, ancorada no ciberjornalismo, desenvolve-se dentro do que se chama Sociedade da Informação. Com tal perspectiva e muita atualidade, cresce a responsabilidade dos profissionais nos planos técnico e ético-deontológico, já que parece ser de grande importância o processo de apuração, hierarquização, organização e apresentação informativa de acordo com as necessidades de cada pessoa (Islas y Gutierrez, 2002, p. XII). É com esta perspectiva que situamos o presente trabalho.

O projeto da Sociedade da Informação é contemporâneo do debate sobre o "fim da história", que, como aponta Martín Becerra, é polêmica suscitada e repercutida internacionalmente pelo autor da tese, Francis Fukuyama (pesquisador acadêmico e ex-assessor do governo dos Estados Unidos), dentro da perspectiva de constituição de uma nova hegemonia mundial capitaneada pelos norte-americanos com a deterioração do bloco soviético-socialista. A queda do Muro de Berlim em 1989 acelerou um processo de redefinição dos projetos globais, ampliando o cenário que sepultava, então, grande parte dos ideais da modernidade, tais como "la convicción del progreso indefinido, la fé en el desarrolllo, la esperanza en el porvenir, la confianza en la integración, y la creencia en la providencia del mercado" (Becerra, 2003, p. 23-24).

Na Sociedade da Informação lou para vários autores Sociedade da Informação e do Conhecimento) e com a convergência tecnológica que abrange o jornalismo, redobra-se, a meu ver, a importância do fazer jornalístico, resultado de uma teoria e de uma ética aplicada ao exercício profissional, com seus valores, métodos e técnicas.

Para Becerra, as ideias-força que regem a chamada Sociedade da Informação amparam-se na desregulamentação, na liberalização e na competição internacional.

$\mathrm{Na}$ Sociedade da Informação (ou para vários autores Sociedade da Informação e do Conhecimento $)^{2}$ e com a convergência tecnológi- ca que abrange o jornalismo, redobra-se, a meu ver, a importância do fazer jornalístico, resultado de uma teoria e de uma ética aplicada ao exercício profissional, com seus valores, métodos e técnicas. Isto hoje parece estar em discussão. E com bastante argumentos razoáveis. Se a informação pode ser obtida por diferentes formas e por distintos protagonistas e fontes e em circuitos que passam à margem do processo tradicional jornalístico, haveria sentido, ainda, durante o século 21, falar em jornalismo profissional, com seus traços distintivos?

O nível atual de concentração de propriedade midiática implica redobrar estudos, verificar empiricamente as conseqüências dela e examinar alguns indícios atuais, como o do risco do processo democrático global, da eficácia das representações do conjunto da Pólis e de uma nova redefinição do que vem a ser esta no século 21.

Para Moraes (2005, p. 83), por exemplo, são essenciais "políticas e inversiones públicas para universalizar los accesos e incrementar los usos sociales, educativos y políticos de las tecnologias digitales".

De certa forma, Sociedade da Informação é um conceito em desenvolvimento que, "impulsionado fundamentalmente por los países centrales, reconoce el protagonismo de las tecnologias de la información y la comunicación (info-comunicación) en la estructuración de las sociedades contemporáneas" (Mastrini, 2006, p. 13).

Conforme Mastrini,

A nível económico, el proyecto argumenta que la centralidad de la información y la comunicación en la estructuración de las sociedades contemporáneas permitirá la obtención de mayores benefícios y un salto a la productividad, con el consecuente crecimiento de las economias. En el plano social, los organismos y gobiernos involuncrados em su desarrollo enfatizan benefícios como consecuencia de la diseminación y ubicuidad de las tecnologias convergentes de la información y comunicación (Mastrini, 2006, p. 14).

No entanto, Mastrini adverte que o projeto SI pode não significar necessariamente maior bemestar social e isso reforça a necessidade de saber a orientação predominante das políticas públicas vinculadas ao tema e de debater e intervir no processo, reforçando tanto a participação social como o encaminhamento de políticas públicas, elementos-chave para o desenvolvimento democrático. 
A questão da falta de acesso às tecnologias ou a falta de conhecimento para aplicá-las tem sido recorrente em muitos autores e debates. $\mathrm{O}$ acesso e o domínio tecnológicos seriam precedentes para uma efetiva participação social nos desdobramentos de uma sociedade democrática. Se de um lado há uma visão tecnocêntrica (em que o livre mercado definirá os rumos da SI), de outro há uma visão sociocêntrica, que pede mecanismos de governança na Internet mais democráticos e uma SI com a participação dos vários setores, como governo, sociedade civil e setor privado, envolvendo a representação dos países, dos mais aos menos desenvolvidos.

E surge uma terceira perspectiva, basicamente envolvendo diferentes organizações da sociedade civil, que questiona a falta de envolvimento dela em temas estratégicos, como o são o financiamento da SI, o reconhecimento da Internet como bem público global, a necessidade de equilíbrio na tomada de decisões e na elaboração de políticas nacionais, regionais e globais (Goldstein, 2006, p. 97-99).

\section{A profissão jornalística, no novo cenário da sociedade da informação e no processo de convergência tecnológica dentro da Pólis como espaço público de discussão do entorno imediato e de suas conseqüências planetárias, reforça, a meu ver, a necessidade de defesa de valores como credibilidade e interesse público.}

Observando-se o volume de dados disponíveis imediatamente, parece-me importante que os princípios de ordem estética, técnica e ética sejam referências para dar inteligibilidade e organização imediata à produção de distintas áreas, mediante critérios profissionais, isto é, consolidados pelas diferentes profissões do campo da mídia. O jornalismo está dentro disso e produz informações e conhecimentos. Eles poderão ser disseminados, certamente, por variados suportes tecnológicos, seja rádio, tevê, jornal, revista, internet.

A profissão jornalística, no novo cenário da sociedade da informação e no processo de convergência tecnológica dentro da Pólis como espaço público de discussão do entorno imediato e de suas conseqüências planetárias, reforça, a meu ver, a necessidade de defesa de valores como credibilidade e interesse público; exige a disse- minação de mensagens precisas, claras e contextualizadas por quaisquer suportes tecnológicos; e requer envolvimento com as novas rotinas profissionais decorrentes do volume de informações, do ritmo social e das demandas específicas informacionais por parte de cada segmento social.

Tal processo se dá, cada vez mais, dentro de sistemas de comunicação globais ou regionais, também cada vez mais complexos e, simultaneamente, com vertentes que apontam para a especialização temática e lingüística, segmentação de veículos e de público, variação geográfica e cultural. Simultaneamente, as barreiras tecnológicas são cada vez mais fáceis de serem ultrapassadas por distintos segmentos sociais ou indivíduos, que podem transmitir e receber quaisquer tipos de informações, seja por meio do uso da palavra ou da imagem.

\section{O jornalismo}

O jornalismo é simultaneamente gerador de informação e produtor de conhecimento. Gerador porque dissemina, de forma massiva, pública e imediata os fatos e versões e interpretações sobre o presente que são referências para as pessoas. Ao levar informação, de diferentes áreas (da biotecnologia ao comportamento individual, da economia à política parlamentar) permite conhecer mais o entorno, por meio de fontes que conhecem ou deveriam conhecer - porque estudam e se envolvem - suas áreas. São especialistas, conhecedores, portadores de conhecimento. O jornalismo pode não ter o conhecimento profundo da sociologia ou da história, da antropologia ou da medicina, mas todas estas áreas se manifestam imediatamente pelo jornalismo, com as especificidades deste, em termos de método, técnica, linguagem, procedimentos ético-deontológicos, estética e outras.

O aperfeiçoamento e a sofisticação do chamado jornalismo investigativo, por exemplo, exige um profissional bastante capacitado para manter o nome de Jornalista, com J maiúsculo. Conforme Santoro, a investigação é a essência do jornalismo, que permanentemente indaga e busca, que enfrenta riscos profissionais e judiciais e, em alguns casos, físicos (Santoro, 2004, p. 17). Quando fala de investigação, o jornalista argentino, vencedor do prêmio Maria Moors Cabot de 2004, destaca que apresenta, basicamente, três características: 1) é realizada pelos jornalistas e não pela justiça nem pela polícia ou por particulares 
interessados; 2) realiza-se superando os obstáculos como os do poder interessado em ocultar as informações; 3) os temas interessam à opinião pública e deixam de lado a vida privada das pessoas, salvo situações-limite, em que se misturam (Santoro, 2004, p. 24-25). Os métodos e os procedimentos; as fontes e os cuidados com a apuração e a persistência; o cruzamento de dados e a busca de documentos públicos são técnicas abordadas minuciosamente por Santoro. A complexidade do trabalho jornalístico é bastante grande.

$\mathrm{O}$ uso da Computer-Assisted Reporting (CAR) - Reportagem Assistida por Computador -, hoje um recurso e um método extremamente valioso para a profissão, tem ajudado sobremaneira em tais investigações. A importância deste tipo de atividade jornalística tem uma legitimidade que repousa na importância imediata para os cidadãos. Estes, embora possam acessar demasiados dados, fontes e sites e mídias em geral, precisam encontrar uma referência comum amparada na credibilidade e na efetiva utilidade para sua vida cotidiana e para a liberdade e consciência no sentido de participar mais concretamente da vida social. Portanto, a confiabilidade do trabalho jornalístico não deve ser perdida ou diluída. A informação precisa, além de veraz, amparar-se no interesse e necessidades sociais. $\mathrm{O}$ surgimento, hoje, de associações de jornalistas investigativos exemplifica a complexidade crescente de um método compartilhado e debatido, capaz de ir a fundo nos grandes temas e problemas, isto é, naquilo que se esconde e que precisa ser desvendado.

Os rankings de violência contra jornalistas, revelados a cada ano por distintas entidades, mostram que, de um lado, os profissionais continuam importantes e, de outro, que a variedade e quantidade de eventos validados como negativos continua a povoar o planeta e que, quanto menos justa e eqüitativa e mais concentradora de poder econômico e político é a sociedade, mais riscos físicos correm os profissionais. Não é à toa, quem sabe, que os menores índices de violência contra jornalistas estejam naqueles países em que a Justiça e o planejamento sociais melhor funcionam, gerando satisfação às demandas sociais e individuais e maior equilíbrio.

Por mais que haja ambiente tecnológico favorável e por mais que haja inclusão social na era digital - e, portanto, acesso e domínio da tecnologia digital e de sua convergência, as sociedades complexas primam pela infinitude do conhecimen- to e, simultaneamente, por seu desdobramento em inúmeros subcampos, que exigem algum conhecimento geral e muitíssimo conhecimento especializado. Isso significa, com algum grau de certeza, que as pessoas terão ainda de viver, por algum razoável tempo histórico, envolvendo-se com as áreas que escolheram ou com as que foram, por falta de opção, obrigadas a assumirem para seu trabalho, para sua dedicação diária.

Uma das conseqüências disso, a meu ver, é a necessidade de alguém trabalhar num campo específico de pautas, busca de informações, detalhamento, contextualização e relato, de forma imediata, com as técnicas textuais capazes de dar visibilidade a uma ou outra área específica e, ao mesmo tempo, permitir certo enlace social dos diferentes campos de conhecimento, seja na cobertura internacional, nacional, regional e local ou de pequenas comunidades; seja nas diferentes temáticas que envolvem a necessidade ou o interesse dos indivíduos.

Em que pese as experiências artesanais, o profissionalismo, que desenvolveu métodos, técnicas e procedimentos de ordem técnica e moral, atinge em cheio, ainda, o conjunto das atividades, seja Medicina, Direito, Engenharia ou Jornalismo. Por isso, as representações e a legitimidade delas são, de determinada forma, respaldadas pela sociedade. Certamente o engenheiro ou o sociólogo não terá a mesma dedicação aos procedimentos de ordem jornalística de um profissional da área, que, por exigência, precisa buscar mais dados imediatos, confrontá-los, ouvir distintas versões, estar presente em acontecimentos e ir em busca de fontes gerais ou específicas, num ritmo tal como desdobra-se do cotidiano.

As ferramentas disponíveis e o acesso a distintas informações e campos do conhecimento, de forma imediata, é ou será mais acessível e isso remete, ao mesmo tempo, para a ideia da continuidade das representações mas, ao mesmo tempo, de uma democracia que, além de representativa, pode ser ainda mais participativa (Prince, 2005, p. 53-72).

Isso vale para a participação mais direta e imediata também nas representações profissionais. Hoje, as críticas aos diversos setores sociais aparecem mais imediatamente pela Internet. O caso do Jornalismo é um exemplo. A opinião e a correção de dados sobre matérias e comentários que se dão na esfera do jornalismo aumentaram significativamente, seja por meio de sítios digitais especializados na área, seja na circulação 
de mensagens entre os próprios membros da comunidade jornalística. Estes, por sua vez, estão conectados com um conjunto de leitores e público em geral, em pequenas cidades ou grandes metrópoles. Os resultados dependerão, claro, do grau de consciência social e política e dos interesses em jogo. Isto porque a formalidade das representações nem sempre significa a efetivação de ideais como liberdade, justiça e desenvolvimento humano e social.

Valores como legitimidade e credibilidade da profissão estão no epicentro da atividade jornalística, com os desdobramentos em valores necessários como liberdade e, simultaneamente, na responsabilidade que exige. Tais elementos tornam-se vigas-mestre da profissão e, conforme Bernier, ampliam o reconhecimento da utilidade e legitimidade do jornalismo dentro de uma sociedade pluralista. E sua credibilidade se assenta no favorecimento que presta à vitalidade da vida democrática (Bernier, 2004, p. 15-23). Isto envolve, claro, não apenas notícias boas ou elogios, mas notícias ruins e críticas duras.

Com diferentes perspectivas e distintas matizes políticas, econômicas e ideológicas, parece haver o reconhecimento das potencialidades das novas tecnologias para a democracia social, para a participação e para as escolhas mais conscientes da sociedade, resultado de um novo cenário ideal. Nele, os interesses midiáticos hegemônicos hoje ficariam mais sob pressão pela vivência cotidiana e expressa por infinitas fontes, em variedade enorme de meios, em diferentes suportes, com controvérsias e discussões e escolhas que poderiam passar ao largo da mediação tradicional midiática, exercida por profissionais a serviço das grandes mídias. Seria um novo espaço, já visível, de novos trabalhos, ocupações, empregos, serviços.

No entanto, o público precisa de um meio que comparta, em escala global, a controvérsia pública, estimulando comentários e repartindo idéias, opiniões, informação e conhecimento, não se reduzindo a grupos étnicos, culturais, sociais, etc. Isso faz com que as experiências sejam, de fato, enriquecedoras, mas insuficientes, não abrindose mão de um sistema de comunicação público e com ressonância social, com estímulo do Estado mas sem seu controle, que caberia à sociedade civil e suas instituições/entidades. A tarefa igualmente não é muito fácil, dado o número de atores, representações e, neste meio, disputas políticas e muitas vaidades pessoais.
Os princípios profissionais, defendidos ao longo do século 20, reafirmam-se como valor moral, mas, ao mesmo tempo, sofrem determinadas e mais complexas coerções, de ordem política, econômica e cultural. Hoje, efetivamente, os conglomerados midiáticos, a mídia cruzada e as megafusões empresariais levam empresas que produzem jornalismo a considerarem tal produção apenas uma das tantas existentes em seus negócios, embora reafirmem, em seus códigos ético-deontológicos, princípios e valores inalienáveis, como verossimilhança, interesse público, isenção, pluralidade, respeito à privacidade, independência, credibilidade, exatidão. Tais princípios encontram-se, portanto, nos documentos produzidos por profissionais e por empresários da área jornalística.

A questão da verdade, por exemplo, essencial como fundamento do trabalho jornalístico e um de seus pilares centrais, não é de fácil viabilização. O fundamento ético, a busca e a operacionalização técnica para que se realize implica diversas gradações de métodos e reflexões. Somente este valor, verdade, implica um traço já bastante preocupante no novo cenário do ciberjornalismo dentro da convergência tecnológica e com a perspectiva de uma sociedade da informação. Há certa complexidade na busca pela verdade, que redobra, atualmente, o trabalho distintivo jornalístico. Conforme Daniel Cornu (1999, p. 321), há uma complexidade das "ordens de verdade":

verdade dos factos (num espírito próximo do cientista), verdade das opiniões e dos julgamentos (fundada sobre uma hermenêutica crítica), verdade das formas de expressão jornalísticas (por analogia à problemática da verdade na arte e na literatura). A complexidade das ordens de verdade supõe por isso um primeiro nível de pluralismo elementar na procura da verdade, que é o dos seus tipos de objectos, sobre o qual se constrói um segundo nível próprio dos sujeitos da procura, inúmeros, porquanto não pode existir 'verdade sem sujeito.

Se a humanidade está cada vez mais entrelaçada em ritmos, interesses e poderes, alguém teria de fazer este trabalho de apuração, busca, disposição de temáticas para constituir um espaço - ainda que com limites de variada ordem - de interlocução pública e coletiva, e expressá-lo de forma imediata, plural, contraditória, polêmica. 
E fazê-lo profissionalmente, como centro de sua atividade cotidiana. A busca pela verdade, reconhecida socialmente e consensuada por verificação, documentação, fatos e versões, é tarefa complexa, mas que se incorpora, gradativamente, a uma cultura profissional que dela depende, como a jornalística. Neste sentido, pode-se defendê-la como socialmente legítima.

\section{Na Sociedade da Informação e diante da} convergência tecnológica, o ethos profissional jornalístico parece, a meu ver, ampliar sua responsabilidade para, de um lado, ter efetiva legitimidade social e, de outro e ao mesmo tempo, ser portador de uma credibilidade que o qualifique para a representação social.

Quem trabalha assim faz de sua atividade precisamente isso, uma profissão comprometida com seu ethos específico e social.

Na Sociedade da Informação e diante da convergência tecnológica, o ethos profissional jornalístico parece, a meu ver, ampliar sua responsabilidade para, de um lado, ter efetiva legitimidade social e, de outro e ao mesmo tempo, ser portador de uma credibilidade que o qualifique para a representação social. No entanto, os possíveis marcos regulatórios no ciberjornalismo enfrentam dificuldades que reforçam a relevância dos aspectos ético-deontológicos em relação ao campo jurídico (Loum, 2004, p. 299-311). Se bem consolidada, tal perspectiva qualifica a representação de mundo que os jornalistas tentam cotidianamente viabilizar. As normas jurídicas, aplicadas à sociedade virtual, têm, ainda menos do que na sociedade não virtual, poucas possibilidades de eficácia significativa.

Assim, a cultura profissional ético-deontológica, com todos os problemas, limites e dilemas cotidianos, constitui ainda um dos principais pilares da atividade jornalística e, por extensão, do ciberjornalismo. O desafio jurídico é o de se redefinir, de forma eficaz e quase simultânea, diante dos impactos de um mundo virtual em que é difícil estabelecer marcos regulatórios ágeis, eficazes e persistentes. Por isso, a questão ética no ciberjornalismo assume uma posição que se antecipa ao Direito ainda de forma mais urgente e complexa do que no jornalismo anterior à convergência tecnológica e à chamada sociedade da informação. Com tal perspectiva, ainda poderíamos chamar jornalismo de Jornalismo.

E os dilemas? A sobreposição da ética ao direito e as escolhas possíveis exigem um alto grau de profissionalismo. E serão objeto, certamente, no exercício técnico e ético da atividade na sociedade da informação e no mundo da convergência tecnológica. É um mundo em que as questões cruciais, diante da convergência, terão mais respostas talvez no campo ético do que no jurídico, redobrando-se a importância das palavras credibilidade e legitimidade.

Por isso, a profissão ganha responsabilidade maior, se quiser permanecer como tal e avançar em sua modificação, atualização e consolidação. Tais aspectos poderão ser levados em conta por não jornalistas, mas com mais dificuldades, a meu ver. Os não jornalistas terão dificuldades, com a mesma intensidade, detalhamento e compromissos, de exercer a atividade como os profissionais da área. Uma coisa é exercer o jornalismo a cada minuto, com sua carga teórica, ética e técnica; outra é ser fonte ou colunista especializado em sua área, atividades em que se é buscado incessantemente pelos profissionais jornalistas ou se pode exercer livremente na mídia, com a autonomia, responsabilidade e opinião próprias do comentarista. Uma coisa é a opinião livre e outra é o compromisso com o desdobramento dos acontecimentos e versões e sua confecção específica com os critérios jornalísticos, entre eles o de relevância, clareza e verossimilhança.

$\mathrm{O}$ fato de tais critérios terem dificuldades de aplicação diante das pressões de ordem política, econômica, ideológica ou mercadológica significa que não há nada mais a fazer e que a profissão chegou ao fim, pelo menos com este nome de Jornalismo e com os valores que se tentou implantar ao longo do século 20? Ou ele ganha fôlego com a sociedade da informação e com a convergência tecnológica, cultivando ainda mais sua especificidade e seus traços distintivos em relação a outras atividades? As condições dadas para a democratização dos processos de comunicação e de informação estão postos. Por que não se realiza plenamente? Qual o papel do Estado e dos profissionais, dos segmentos sociais e das organizações para implementar o projeto democrático na mídia?

A preocupação ética cresce na medida em que aumenta, nas sociedades contemporâneas (em que se reconhece, como retórica e como configuração jurídica, uma certa variedade de valores 
emancipatórios e de direitos, ao menos consagrados em muitos países, fruto da modernidade), o recrudescimento de valores e ações que geram a xenofobia, a intolerância política e religiosa, a discriminação sexual e étnica, a violência, a criminalidade, a incapacidade física e/ou mental, as catástrofes ambientais.

Isto implica um conjunto de questões comuns ao jornalismo, dada sua responsabilidade por temas, fatos e versões da atualidade, que emergem a cada minuto no planeta. E exige uma crescente especialização para tratar de temas tão complexos e com tantas vertentes.

Diante de tal perspectiva, os indivíduos e os movimentos sociais, os setores segmentados, entidades e instituições públicas e privadas preocupados com a informação do tipo jornalística têm um cenário - embora desfavorável no plano global hegemonizado pelo fundamentalismo de mercado - favorável para a realização de projetos que apontem para a democracia e para a melhor consecução da atividade jornalística, com seus critérios éticos e técnicos qualificados.

Observando-se a produção atual de conhecimento e de fatos, que circulam de diferentes formas, de bibliotecas a veículos jornalísticos voltados para uma pequena comunidade, exigindo acompanhamento, seletividade e determinado ritmo; envolvendo interesses e necessidades específicas e imediatas, em fluxos internacional ou local; exigindo divisão de funções ao mesmo tempo em que pede profissionais multimídia para quaisquer plataformas tecnológicas; exigindo-se distinção no tratamento do conhecimento, do fato ou das fontes nos diversos gêneros e nas diferentes editorias; exigindo-se capacidade de apurar e de editar, de pautar e de entrevistar, de coletar e de redigir, de investigar e de conferir... Vê-se que a tarefa é complexa. Além disso, é importante "traduzir" campos herméticos e buscar certa isenção ao lidar com pontos de vista que podem ser até mesmo contrários ao do profissional. Assim, certamente o sistemático aprendizado e a continuada experiência cotidiana podem pedir um campo distintivo profissional, um campo de aprendizado, de saber e de trabalhar/aplicar específicos. Isso poderia atestar, ainda, que a legitimidade e a credibilidade são dois pilares centrais da atividade jornalística, amparados, entre outros, nos valores de representação/delegação, responsabilidade e liberdade, que não constituem, senão, bases dos próprios direitos civis nas sociedades democráticas.

\section{Considerações finais}

Embora a mídia e o jornalismo tendam a fornecer um grau de satisfação de acordo com as demandas individuais de variadas ordens, não se deve esquecer que os indivíduos não têm um momento de chegada que os satisfaça plenamente a ponto de não querer seguir adiante (com exceção dos que desistiram do mundo - e mesmo assim não por satisfação). Este cenário individual, que se reflete no movimento cotidiano das sociedades, exige algumas satisfações informativas, que tenham a ver com seu mundo imediato, com sua realidade cotidiana, com seus interesses e necessidades diários. Isto não ocorreria apenas se os indivíduos estivessem plenamente realizados e as sociedades fossem justas e satisfatórias e os governos/empresas/estados correspondessem à vida plena em termos de bem-estar, em todas as áreas, da educação à saúde, da habitação à alimentação, do lazer ao consumo.

A segmentação e diversidade favorecem o conhecimento sobre a multiplicidade do presente, envolto por distintas áreas com deficiência informacional e de conhecimento. Favorecem e criam ambiente propício para versões não visíveis na mídia tradicional, para fontes pouco ouvidas, para interpretações mais contextualizadas. São informações e relatos sobre o conhecimento e sobre a cultura produzidos em diferentes âmbitos.

É necessário, no entanto, uma repartição comum que suscita comentários e isso parece exigir, além de meios segmentados, meios também compartilhados em grande escala social.

Diante de tal perspectiva, os indivíduos e os movimentos sociais, os setores segmentados, entidades e instituições públicas e privadas preocupados com a informação do tipo jornalística têm um cenário - embora desfavorável no plano global hegemonizado pelo fundamentalismo de mercado - favorável para a realização de projetos que apontem para a democracia e para a melhor consecução da atividade jornalística, com seus critérios éticos e técnicos qualificados. 


\section{REFERÊNCIAS}

BECERRA, Martín. Sociedad de la Información: proyecto, convergencia, divergencia. Bogotá: Norma, 2003.

BERNIER, Marc-François. Éthique et Deontologie du Journalisme. Saint-Nicolas: Les Presses de l'Université Laval, 2004.

CORNU, Daniel. Jornalismo e Verdade: para uma ética da informação. Lisboa: Instituto Piaget, 1999.

ISLAS, Octavio y GUTIERREZ, Fernando. Introducción. In: ISLAS, Octavio et allii (Coord.). Explorando el Ciberperiodismo Iberoamericano. México: Compañia Editorial Continental, 2002.

GOLDSTEIN, Roxana. Aportes para el debate sobre el impacto de la CMSI en el desarrollo para América Latina: los conflictos en torno a la brecha digital y a la gobernanza de Internet. In: MASTRINI, Guillermo y CALIFANO, Bernadette (Comp.). Sociedad de la Información en la Argentina: políticas públicas y participación social. Buenos Aires: Fundación Friedrich Ebert, 2006.

LOUM, Ndiaga. Internet y regulación: la ética y la deontología prevalecen sobre el derecho. In: CROVI DRUETTA, Delia (Coord.). Sociedad de la información y el conocimiento: entre lo falaz y lo posible. Buenos Aires: La Crujía, 2004.

MASTRINI, Guillermo. Introducción. In: MASTRINI, Guillermo y CALIFANO, Bernadette (Comp.). Sociedad de la información en la Argentina: políticas públicas y participación social. Buenos Aires: Fundación Friedrich Ebert, 2006.

MORAES, Dênis de. Cultura mediática y poder mundial. Bogotá: Norma, 2005.

PRINCE, Alejandro E-democracia y desarrollo: limites politológicos. In: FINQUELIEVICH, Susana (Coord.). Desarrollo local en la sociedad de la información: municípios e internet. Buenos Aires: La Crujía, 2005.
SANTORO, Daniel. Técnicas de investigación: métodos desarrollados en diarios y revistas de América Latina. México: FCE/FNPI, 2004.

\section{NOTAS}

1 Os documentos e reuniões fundamentando o projeto SI e seu desdobramento, especialmente nos países europeus e Estados Unidos, estão detalhados em muitos livros, artigos e sítios digitais. Para o presente trabalho, utilizo alguns dos estudos referenciais que envolvem a América Latina e dão panorama global sobre a questão, seja a SI ou SIC, entre eles os de Martín Becerra e os organizados por Guillermo Mastrini e Elizabeth Califano, por Delia Crovi Druetta e por Susana Finquelievich. Neles, entre outros aspectos analisados, encontram-se as perspectivas, problemas, contradições, possibilidades e limites, balanço regional e internacional e vertentes político-econômicas e ideológicas da Sociedade da Informação/Sociedade da Informação e do Conhecimento, sempre com fornecimento de dados.

2 Os documentos e reuniões fundamentando o projeto SI e seu desdobramento, especialmente nos países europeus e Estados Unidos, estão detalhados em muitos livros, artigos e sítios digitais. Para o presente trabalho, utilizo alguns dos estudos referenciais que envolvem a América Latina e dão panorama global sobre a questão, seja a SI ou SIC, entre eles os de Martín Becerra e os organizados por Guillermo Mastrini e Elizabeth Califano, por Delia Crovi Druetta e por Susana Finquelievich. Neles, entre outros aspectos analisados, encontram-se as perspectivas, problemas, contradições, possibilidades e limites, balanço regional e internacional e vertentes político-econômicas e ideológicas da Sociedade da Informação/Sociedade da Informação e do Conhecimento, sempre com fornecimento de dados. 